\title{
INDEPENDENT FACTORS ASSOCIATED WITH LONGEVITY OF PROSTHETIC PULMONARY VALVES AND VALVED CONDUITS
}

Christopher A. Caldarone, $\mathrm{MD}^{\mathrm{a}}$

Brian W. McCrindle, MD, MPH

Glen S. Van Arsdell, MDa

John G. Coles, MD

Gary Webb, MD

Robert M. Freedom, MD

William G. Williams, MD
Objective: To evaluate the age dependence of variables predictive of pulmonary valve prosthesis replacement, we conducted the following analysis.

Methods: Retrospective analysis of 945 operations in 726 patients undergoing placement of pulmonary valve prostheses was performed. Age was identified as a strong independent predictor of valve failure. The database was stratified into age-based subsets and predictors of valve replacement were identified within each subset.

Results: For the entire cohort, freedom from valve replacement at 5 years was $81 \%$. Younger age was strongly associated with decreased time to valve replacement by multivariable analysis (hazard ratio: $0.71 / \log$-year, $P<.001$ ). Other independent factors included diagnosis, type of prosthesis, and timedependent requirement for pulmonary valve stent placement. Important predictors of valve failure varied among age groups and are as follows: for age less than 3 months: valve type; for age 3 months to less than 2 years: smaller normalized valve prosthesis size; for age 2 years to less than 13 years: sex, smaller normalized valve prosthesis size, placement of endovascular stents, and valve type; for age 13 years to 65 years: smaller normalized valve prosthesis size, placement of endovascular stents, and increased number of previous valve placements.

Conclusion: Age is a dominant risk factor predictive of pulmonary valve prosthesis failure. A significant interaction exists between age and the effects of diagnosis, valve type, and size on prosthetic pulmonary valve longevity. (J Thorac Cardiovasc Surg 2000;120:1022-31)
$P$ lacement of a valve or valved conduit in the pulmonary circulation during repair of congenital heart defects is problematic in that most of these prostheses will eventually require replacement. Therefore, consequences of the choice of prosthesis extend far beyond

From the Divisions of Cardiovascular Surgery a and Cardiology, ${ }^{\mathrm{b}}$ The Hospital for Sick Children, and the University of Toronto Faculty of Medicine, Toronto, Ontario, Canada.

Read at the Eightieth Annual Meeting of The American Association for Thoracic Surgery, Toronto, Ontario, Canada, April 30-May 3, 2000.

Received for publication May 4, 2000; revisions requested June 20, 2000; revisions received July 25, 2000; accepted for publication Aug 4, 2000.

Address for reprints: Christopher A. Caldarone, MD, Division of Cardiovascular Surgery, The University of Iowa Hospitals and Clinics, 200 Hawkins Dr, 1616A-JCP, Iowa City, IA 52242-1083 (E-mail: chris-caldarone@uiowa.edu).

Copyright $\odot 2000$ by The American Association for Thoracic Surgery $0022-5223 / 2000 \$ 12.00+0 \quad \mathbf{1 2 / 6 / 1 1 0 6 8 4}$

doi: $10.1067 / \mathrm{mtc} .2000 .110684$ the initial palliative operative period. The dominant issue in the patient's long-term course often becomes subsequent prosthesis replacements.

Previous studies ${ }^{1-4}$ have evaluated factors associated with freedom from reoperation for pulmonary valve replacement. Factors commonly reported as important are valve type and size, age of patient, and diagnosis. Many studies, however, are limited to a single valve type (eg, allografts) and attempt to identify important predictors for valve survival within the context of the particular valve type being studied. For the surgeon to choose between different types of valve prostheses for an individual patient, however, he or she must compare the results of these disparate studies to arrive at the optimum choice. Comparison between studies limited to a single valve type is problematic in that patient selection bias and institution-related factors may limit the ability to make valid comparisons.

Comparison among studies limited to a single valve type can also be problematic because age is frequent- 
Table I. Type of valve prosthesis stratified by number of previous prosthesis placements

\begin{tabular}{|c|c|c|c|c|c|}
\hline & \multirow[b]{2}{*}{ Valve type used } & \multicolumn{4}{|c|}{ Valve prosthesis placement } \\
\hline & & First & Second & Third or more & Total \\
\hline \multirow[t]{2}{*}{ Allograft $(n=396)$} & Aortic & 141 & 23 & 3 & 167 \\
\hline & Pulmonary & 176 & 44 & 9 & 229 \\
\hline \multirow[t]{2}{*}{ Pericardial $(n=112)$} & Ionescu-Shiley & 58 & 5 & 0 & 63 \\
\hline & Mitroflow & 34 & 12 & 3 & 49 \\
\hline \multirow[t]{3}{*}{ Porcine $(n=343)$} & Carpentier-Edwards & 83 & 30 & 5 & 118 \\
\hline & Hancock & 145 & 50 & 14 & 209 \\
\hline & Medtronic Intact & 14 & 2 & 0 & 16 \\
\hline Polystan $(n=79)$ & Polystan & 67 & 11 & 1 & 79 \\
\hline Other $(n=15)$ & & 8 & 6 & 1 & 15 \\
\hline Totals & & 726 & 183 & 36 & 945 \\
\hline
\end{tabular}

Manufacturers: Shiley, Inc, Irvine, California; Sulzer Mitroflow Corporation, Richmond, British Columbia, Canada; Baxter Healthcare Corporation, Edwards Division, Santa Ana, California; Medtronic, Inc, Minneapolis, Minnesota; Polystan A/S, Copenhagen, Denmark.

ly an important predictor of valve survival. ${ }^{1,4-6}$ Inasmuch as the age of the cohort studied often varies between studies, it may be inappropriate to make direct comparisons between such studies. For example, a study of allografts in children (median age 6.5 years) by Weipert and associates ${ }^{7}$ is difficult to compare with a study in children (median age 14 years) by Niwaya and associates. ${ }^{6}$

With these difficulties in mind, we sought to explore the relationship between age and freedom from pulmonary valve prosthesis replacement in a large singleinstitution database encompassing a wide spectrum of valve types and a broad age range. Our first step in the analysis was to define the relationship between age and freedom from valve replacement and to confirm the statistical significance of this relationship. This would then allow us to approach our primary objective, which was to explore the variation in predictors of valve survival across clinically relevant age-based strata.

\section{Methods}

Study population. We examined the records of all patients undergoing placement of a valve or valved conduit in the pulmonary circulation for congenital heart disease between June 1966 and December 1996 using the combined database of The Hospital for Sick Children/Toronto Congenital Cardiac Centre for Adults. A total of 726 patients undergoing 945 operations were identified. Choice of conduits was at the discretion of the surgeon but was restricted by size of the patient and availability of allografts of appropriate size.

Patient follow-up was obtained through review of medical records, clinic visits, and direct telephone contact. Follow-up was considered complete if the patient's status was determined after June 1997. The median duration of follow-up was 8.3 years (range birth to 31.5 years) and $93 \%$ of survivors had complete follow-up.
Valve survival. Valve survival is defined as the interval between implantation of a device in the pulmonary circulation and the date of reoperation for valve replacement. Patients not requiring valve replacement were treated as censored events at the time of last clinical contact or the death of the patient. Because many patients had multiple valve replacements, the same patient may have provided data for more than one interval. Each valve survival interval was treated as an independent event.

Pulmonary valve sizes. So that valve sizes could be compared across a broad range of age groups, the predicted pulmonary anulus size was calculated according to the data of Rowlatt, Rimoldi, and Lev. ${ }^{8}$ The size of the valve prosthesis was then compared with the predicted pulmonary anulus size, and a z-score was developed that described the number of standard deviations between the size of the pulmonary valve prosthesis and the predicted average pulmonary anulus diameter.

Data analysis. Data are described as frequencies, medians with ranges, or means with standard deviations as appropriate. The Cox proportionate hazard modeling was used to determine both univariable and multivariable relationships between time to reintervention for conduit or valve replacement and explanatory variables. SAS Version 6.12 statistical software (SAS Institute, Inc, Cary, NC), set to default settings, was used to perform all statistical analyses.

\section{Results}

Study population. The median age of the entire cohort is 6.2 years (range 1 day-65 years). General characteristics of the population are summarized in Table I. Approximately $25 \%$ of the patients underwent at least two pulmonary valve placement procedures. The devices implanted were grouped into three major categories (allograft, pericardial, and porcine) and two minor categories (Polystan conduits [Polystan A/S, Copenhagen, Denmark] and miscellaneous). The mis- 

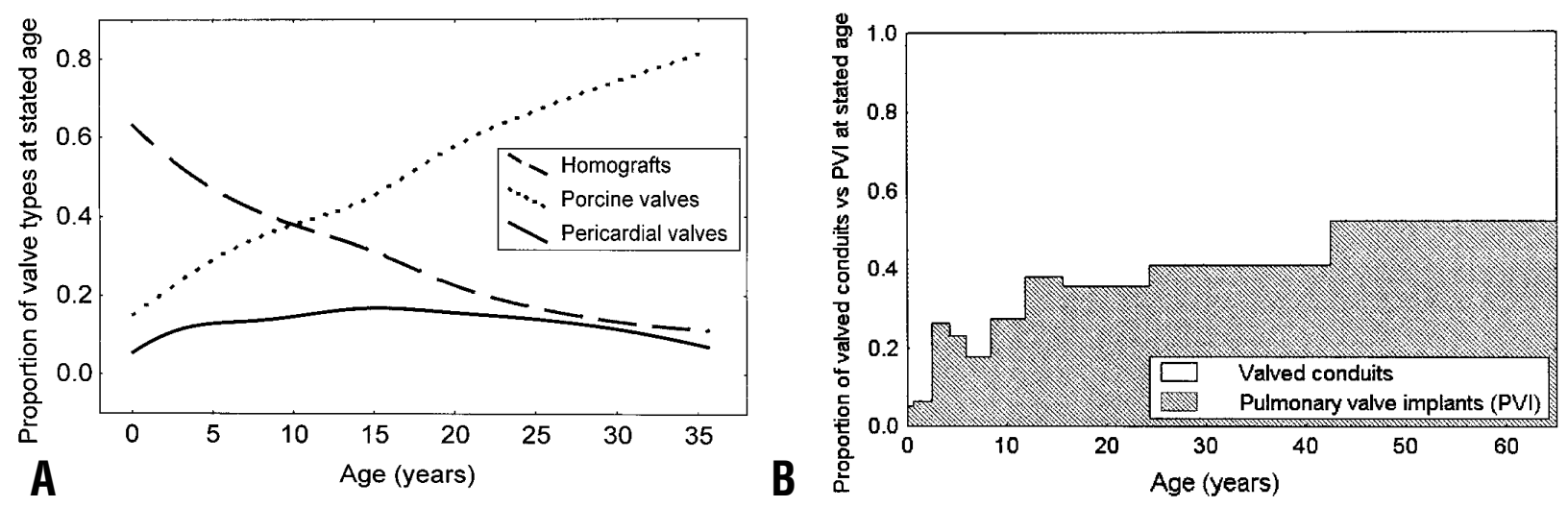

Fig 1. A, The graph demonstrates the relative distribution of valve types used as a function of age at surgery. Homografts are the most commonly used valves in the younger patients and porcine valves are most commonly used in the older patients. B, The relative distribution of valve placement techniques is plotted as a function of age at surgery. The use of valved conduits predominates in the younger patients. In contrast, as patient age increases, the use of the pulmonary valve implant $(P V I)$ technique increases in frequency.

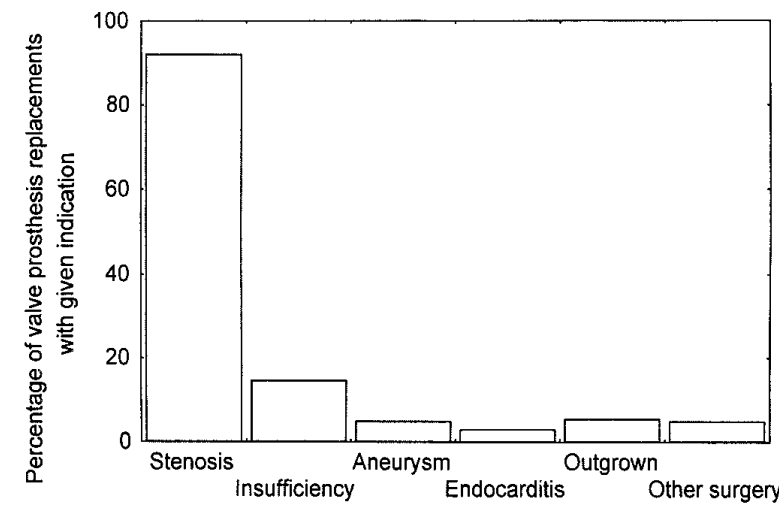

Fig 2. The percentage of prosthesis replacements with a given indication are plotted. Note that an individual patient may have multiple diagnoses at the time of prosthesis replacement (eg, stenosis and insufficiency). "Other surgery" signifies patients in whom a prosthesis was replaced expectantly as a secondary portion of a separate cardiac procedure.

cellaneous category ("other") included any valve type used in 4 or fewer patients. The choice of valve prosthesis varied across the age range of the cohort. In general, homografts were most commonly used in the youngest patients and porcine valves were most commonly used in the older patients (Fig 1, A).

The techniques used for valve placement varied with age. Valved conduits were commonly used in the younger patient groups in which discontinuity of the ventriculopulmonary connection was more frequently present (eg, truncus arteriosus). In contrast, in the older age groups, in which continuity between the heart and pulmonary arteries was more frequently present (eg, tetralogy of Fallot with pulmonary insufficiency), orthotopically placed pulmonary valve implants ${ }^{3}$ were used with increasing frequency (Fig 1,B).

The indications for replacement of a failed pulmonary valve prosthesis are summarized in Fig 2. The majority of replacements were associated with some degree of stenosis. The clinical threshold for consideration of prosthesis replacement can be expected to have varied between individual patients over the study period. In general, a right ventricular systolic pressure greater than $60 \%$ of the systemic pressure or, in the presence of pulmonic insufficiency, increasing right ventricular dimensions, arrhythmias, or onset of tricuspid insufficiency were considered indications for replacement of a pulmonary valve prosthesis.

The diagnostic categories of the patients undergoing initial pulmonary valve or valved conduit replacement are summarized in Table II. Pulmonary atresia with ventricular septal defect, truncus arteriosus, and tetralogy of Fallot were the most common diagnoses, comprising almost $60 \%$ of the patients. Allografts were most frequently used in patients with pulmonary atresia and ventricular septal defect and in those with truncus arteriosus. Pericardial valves were most frequently used in patients with tetralogy of Fallot. Porcine valve use was more evenly distributed among patients with tetralogy, truncus, and transposition of the great arteries. Finally, use of the Polystan conduit was generally limited to patients with double-outlet right ventricle, pulmonary atresia, and truncus arteriosus. 
Table II. The type of valve prosthesis is tabulated against diagnosis

\begin{tabular}{|c|c|c|c|c|c|c|c|}
\hline \multirow[b]{2}{*}{ Primary diagnosis } & \multirow[b]{2}{*}{ No. } & \multirow[b]{2}{*}{$\%$} & \multicolumn{5}{|c|}{ Number of prostheses used per each diagnosis } \\
\hline & & & Allograft & Pericardial & Porcine & Polystan & Other \\
\hline $\mathrm{PA} / \mathrm{VSD}$ & 185 & 19.6 & 110 & 11 & 44 & 15 & 5 \\
\hline Truncus arteriosus & 173 & 18.3 & 94 & 2 & 46 & 29 & 2 \\
\hline ToF & 168 & 17.8 & 33 & 50 & 75 & 8 & 2 \\
\hline D-TGA & 100 & 10.6 & 40 & 1 & 53 & 6 & 0 \\
\hline L-TGA & 95 & 10.1 & 38 & 0 & 52 & 4 & 1 \\
\hline ToF/absent PV & 85 & 9.0 & 27 & 23 & 28 & 4 & 3 \\
\hline DORV & 65 & 6.9 & 27 & 3 & 23 & 12 & 0 \\
\hline Other & 28 & 3.0 & 17 & 3 & 8 & 0 & 0 \\
\hline PS & 23 & 2.4 & 6 & 7 & 7 & 1 & 2 \\
\hline PA/IVS & 20 & 2.1 & 4 & 12 & 4 & 0 & 0 \\
\hline Tricuspid atresia & 3 & 0.3 & 0 & 0 & 3 & 0 & 0 \\
\hline Total & 945 & 100.0 & 396 & 112 & 343 & 79 & 15 \\
\hline
\end{tabular}

$P A / V S D$, Pulmonary atresia with ventricular septal defect; $T o F$, tetralogy of Fallot; $T G A$, transposition of the great arteries; $P V$, pulmonary valve; $D O R V$, double-outlet right ventricle; $P S$, pulmonic stenosis; $P A / I V S$, pulmonary atresia with intact ventricular septum.

Fig 3 shows a plot of Kaplan-Meier estimates of freedom from valve replacement (deaths were censored). The freedom from valve replacement at 5 years is $82 \%$; at 10 years, $58 \%$; and at 15 years, $41 \%$. In Cox proportionate hazard modeling, factors associated with a decreased time to valve replacement were sought first in univariable analysis (Table III). Significant factors in univariable analysis of the entire database included younger patient age at surgery, some cardiac diagnoses, second procedures (first replacement of a failed prosthesis), some prosthesis types, and the need for endovascular stent implantation. Nonsignificant factors in the univariable analysis of the entire database included sex, date of valve implantation, and decreasing pulmonary valve prosthesis z-score.

Effect of age at surgery on time to valve replacement. Younger age at surgery appeared to be strongly associated with a reduced time to valve replacement in both univariable and multivariable analyses. The relationship also appeared to be nonlinear. This relationship was further explored by categorizing the variable age at surgery into groups of about 50 procedures each. These variables were then entered as dummy variables into a final multivariable Cox proportionate hazard model controlling for sex, pulmonary valve prosthesis $\mathrm{z}$-score, cardiac diagnosis, and the time-dependent use of endovascular stents. The age category 15 to 18 years was used as the reference category, and the parameter estimates were converted to hazard ratios. Fig 4 is a plot of the hazard ratios and again shows the nonlinear risk relationship with time to valve replacement.

The dominance of age as a risk factor for valve replacement in the younger age groups is graphically represented in Fig 4. The adjusted plot takes into account the contribution of sex, cardiac diagnosis, valve type, pulmonary valve $\mathrm{z}$-score, and valve type in the multivariable Cox proportionate hazard modeling. The effect of adjusting for these other variables has a relatively small effect on the hazard ratio, most notably in the younger patients.

Age-stratified analysis. On the basis of the relationships shown in Fig 4, the knowledge that some of the risk factors were not present in some age groups, and an interest in which risk factors predominated in which age groups (interaction), we divided the study population into 4 age categories and performed a stratified analysis of time to valve replacement. The age categories were less than 3 months $(n=122), 3$ months to less than 2 years $(\mathrm{n}=107), 2$ years to less than 13 years $(\mathrm{n}=456)$, and 13 to 65 years $(\mathrm{n}=260)$. These categories were chosen on the basis of knowledge about the distribution of risk variables and the magnitude of the hazard ratios across the smaller age categories, as noted in Fig 4, with smaller categories with similar hazard ratios being grouped together. Results of this analysis are given in Table IV.

Age less than 3 months at surgery. For the 122 procedures, the median age at surgery was 17 days. The unadjusted hazard ratio for risk of valve failure relative to all other age categories was 4.02 (95\% confidence limits [CL]: 2.73-5.93). All implants were the initial procedure. Truncus arteriosus in 92 patients was the predominant diagnosis, with pulmonary atresia with ventricular septal defect in 10 and a heterogeneous group of other lesions in 20 patients. Valve type implanted included aortic homograft conduits in 44 patients, pulmonary homograft conduits in 33 , Polystan conduits in 22 , porcine valved conduits in 17 , and other 


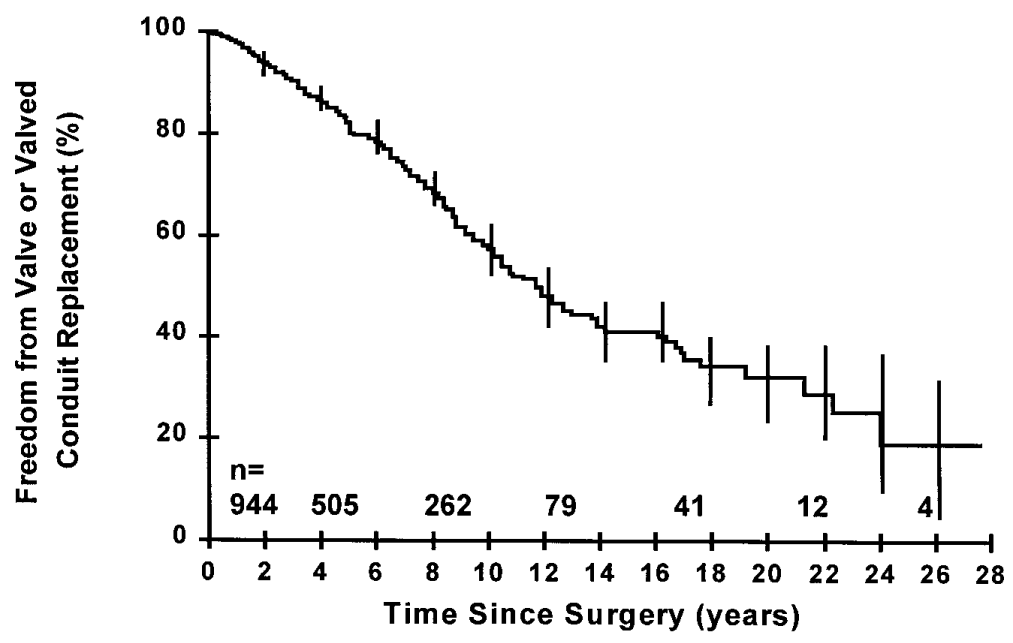

Fig 3. Kaplan-Meier estimates of freedom from valve replacement. Vertical lines represent $95 \%$ confidence intervals. The freedom from valve replacement at 5 years is $82 \%$, at 10 years is $58 \%$, and at 15 years is $41 \%$.

types in 6 patients. In the univariable Cox proportionate hazard modeling, time to valve replacement was not significantly related to age and sex, date of surgery, cardiac diagnosis, pulmonary valve prosthesis z-score, or the time-dependent use of endovascular stents. Time to valve replacement was significantly related only to valve type $(P=.04)$, with hazard ratios as follows: pulmonary homograft conduit (reference category); aortic homograft conduit, 1.59; porcine valved conduit, 4.08; Polystan valved conduit, 5.42; and other types, 0.76.

Age 3 months to less than 2 years at surgery. For the 107 procedures, the median age at surgery was 11.3 months. The unadjusted hazard ratio for risk of valve failure relative to all other age categories was 2.59 (95\% CL: 1.78-3.75). Truncus arteriosus $(n=36)$ and pulmonary atresia with ventricular septal defect $(n=$ 33) were the predominant cardiac diagnoses, and valved conduits (mainly homografts) were the predominant valve type. The only variable significantly associated with a reduced time to valve replacement was a smaller pulmonary valve prosthesis z-score $(P=.02)$, with a hazard ratio of 0.75 per 1 standard deviation increment.

Age 2 years to less than 13 years at surgery. For the 456 procedures, the median age at surgery was 6.0 years. The unadjusted hazard ratio for risk of valve failure relative to all other age categories was 1.54 (95\% CL: 1.19-2.00). Pulmonary atresia with ventricular septal defect $(n=121)$, tetralogy of Fallot $(n=74)$, and transposition of the great arteries $(n=62)$ were the predominant cardiac diagnoses. Porcine valved conduits $(\mathrm{n}=111)$, pulmonary homograft conduits $(\mathrm{n}=111)$, aortic homograft conduits $(n=69)$, and pericardial valves $(n=66)$ were the predominant valve types. Significant factors in univariable analysis associated with a reduced time to valve replacement included male sex $(P=.04$; hazard ratio 1.41$)$, smaller pulmonary valve prosthesis $\mathrm{z}$-score $(P=.04$; hazard ratio 0.93 per 1 standard deviation increment), the timedependent use of endovascular stents $(P=.02$; hazard ratio 2.02$)$, and valve type $(P=.008)$. Hazard ratios for valve type are as follows: pulmonary homograft conduit, reference category (1.00); porcine valved implant, 1.12; pericardial valve implant, 1.70; aortic homograft conduit, 1.87; homograft valve implant, 1.97; porcine valved conduit, 2.00; and Polystan valved conduit, 3.50. Time to valve replacement was not significantly related to age or date of surgery, cardiac diagnosis, or number of procedure.

Age 13 to 65 years at surgery. For the 260 procedures, the median age was 19 years. The unadjusted hazard ratio for risk of valve failure relative to all other age categories was 0.19 (95\% CL: 0.12-0.28). Tetralogy of Fallot $(\mathrm{n}=80)$, ventricular inversion (Ltransposition of the great arteries, $n=45$ ), and transposition of the great arteries $(n=34)$ were the predominant cardiac diagnoses. Porcine valved conduits $(\mathrm{n}=$ 97), porcine valved implants $(n=62)$, and pericardial valve implants $(\mathrm{n}=38)$ were the predominant valve types. The procedure was the second procedure in 82 patients and the third or more procedure in 21 patients. Time to valve replacement was significantly related to the number of the procedure $(P<.001)$, with hazard ratios relative to an initial procedure (reference catego- 
Table III. Associations between explanatory variables and time to valve or valved conduit replacement

\begin{tabular}{|c|c|c|c|c|c|c|c|c|}
\hline \multirow[b]{2}{*}{ Variable } & \multicolumn{4}{|c|}{ Univariable analysis } & \multicolumn{4}{|c|}{ Multivariable analysis } \\
\hline & Estimate & $S E$ & Hazard ratio & $\mathrm{P}$ value & Estimate & $S E$ & Hazard ratio & $\mathrm{P}$ value \\
\hline \multicolumn{9}{|l|}{ Sex } \\
\hline Male & \multicolumn{2}{|c|}{ Reference category } & & & \multicolumn{2}{|c|}{ Reference category } & & \\
\hline Female & -0.1090 & 0.1276 & 0.90 & .40 & -0.1856 & 0.1383 & 0.83 & .18 \\
\hline Age at surgery (log-y) & -0.3386 & 0.0295 & 0.71 & $<.001$ & -0.3455 & 0.0473 & 0.71 & $<.001$ \\
\hline \multicolumn{9}{|l|}{ Cardiac diagnosis } \\
\hline ToF & \multicolumn{2}{|c|}{ Reference category } & & & \multicolumn{2}{|c|}{ Reference category } & & \\
\hline Pulmonary atresia/VSD & 1.0194 & 0.2393 & 2.77 & $<.001$ & 0.7843 & 0.2623 & 2.19 & .003 \\
\hline Truncus arteriosus & 1.4680 & 0.2466 & 4.34 & $<.001$ & 0.5668 & 0.3235 & 1.76 & .08 \\
\hline D-TGA & 0.9765 & 0.2528 & 2.66 & $<.001$ & 0.9566 & 0.2872 & 2.60 & $<.001$ \\
\hline L-TGA & 0.6882 & 0.2632 & 1.99 & .009 & 0.8468 & 0.2934 & 2.33 & .004 \\
\hline ToF/absent PV & 0.6245 & 0.2642 & 1.87 & .02 & 0.5528 & 0.2802 & 1.74 & $<.05$ \\
\hline DORV & 1.3296 & 0.2833 & 3.78 & $<.001$ & 1.2720 & 0.3073 & 3.57 & $<.001$ \\
\hline Critical PV stenosis & 0.0942 & 0.5370 & 1.10 & .87 & 0.0304 & 0.5487 & 1.03 & .96 \\
\hline PA/IVS & 0.8032 & 0.4240 & 2.23 & .06 & 0.6427 & 0.4390 & 1.90 & .15 \\
\hline Other type of anomaly & 0.6377 & 0.4861 & 1.89 & .19 & 0.6900 & 0.4944 & 1.99 & .17 \\
\hline Date of surgery (per consecutive 5 years) & 0.0640 & 0.0621 & 1.07 & .30 & 0.0132 & 0.0818 & 1.01 & .88 \\
\hline \multicolumn{9}{|l|}{ Procedure number } \\
\hline Initial & \multicolumn{2}{|c|}{ Reference category } & & & \multicolumn{2}{|c|}{ Reference category } & & \\
\hline Second & -0.3804 & 0.1852 & 0.68 & .04 & -0.1717 & 0.2047 & 0.84 & .41 \\
\hline Third greater & 0.1671 & 0.3414 & 1.18 & .69 & 0.3525 & 0.3752 & 1.42 & .35 \\
\hline PV prosthesis z-score* & -0.0552 & 0.0295 & 0.95 & .06 & -0.0396 & 0.0329 & 0.96 & .23 \\
\hline \multicolumn{9}{|l|}{ Prosthesis type } \\
\hline PV homograft conduit & \multicolumn{2}{|c|}{ Reference category } & & & \multicolumn{2}{|c|}{ Reference category } & & \\
\hline AV homograft conduit & 0.6349 & 0.2062 & 1.89 & .002 & 0.6003 & 0.2105 & 1.82 & .005 \\
\hline PV or AV homograft implant $\dagger$ & 0.1350 & 0.3311 & 1.15 & 69 & 0.7924 & 0.3896 & 2.21 & $<.05$ \\
\hline Porcine valve conduit & 0.1375 & 0.1971 & 1.15 & .49 & 0.5867 & 0.2280 & 1.80 & .02 \\
\hline Porcine valve implant & -0.7159 & 0.3865 & 0.49 & .07 & 0.4630 & 0.4323 & 1.59 & .29 \\
\hline Polystan valved conduit & 1.2001 & 0.2181 & 3.32 & $<.001$ & 1.2204 & 0.2370 & 3.39 & $<.001$ \\
\hline Pericardial valve implant & -0.2113 & 0.2387 & 0.81 & .79 & 0.6404 & 0.2970 & 1.90 & .04 \\
\hline Endovascular stent implantation & 1.2625 & 0.1981 & 3.53 & $<.001$ & 0.6034 & 0.2335 & 1.83 & .01 \\
\hline
\end{tabular}

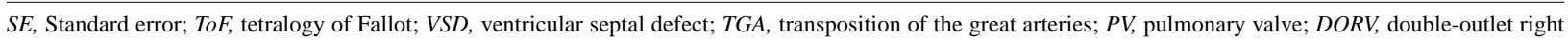
ventricle; $P A / I V S$, pulmonary atresia with intact ventricular septum; $A V$, aortic valve.

*Based on predicted pulmonary valve anulus based on patient's body surface area.

$\dagger$ Implant refers to placement of a valve prosthesis in the orthotopic position without a conduit.

\$ntered as time-dependent explanatory variable.

ry) for second procedures of 0.55 and for third or greater procedures of 8.76 . Reduced time to valve replacement was also related to smaller pulmonary valve prosthesis $\mathrm{z}$-score $(P=.01$; hazard ratio 0.83 per 1 standard deviation increment), and the time-dependent use of endovascular stents $(P<.001$; hazard ratio 31.0). Time to valve replacement was not significantly related to sex, age, date of surgery, cardiac diagnosis, or valve type.

\section{Discussion}

Use of a valve or valved conduit to create continuity between the ventricle and pulmonary circulation has become an integral part of the surgical therapy for many complex congenital heart lesions. The valve prosthesis used in such therapy, however, has been described as a "weak facet" of reconstructive surgery because of the inevitable need for its replacement. ${ }^{4}$ In choosing a valve prosthesis for a patient, the surgeon must assimilate data from numerous series with limited similarities in patient ages, diagnoses, and types of devices studied. On the basis of this information, the surgeon must select the valve prosthesis most likely to provide the greatest durability and, thus, freedom from reoperation.

In the present study, the experience at a single institution has been analyzed to identify predictors of pulmonary valve prosthesis failure. The breadth of the cohort in terms of valve prosthesis types, implantation techniques (pulmonary valve implant or conduit), and diagnoses across an age range of 65 years provides some advantages in the statistical analysis. Specifically, 
Table IV. Predictors of valve prosthesis failure by age-based strata

\begin{tabular}{|c|c|c|c|}
\hline Age group & Variable & Hazard ratio & $\mathrm{P}$ value \\
\hline \multirow[t]{6}{*}{$<3 \mathrm{mo}(\mathrm{n}=122)$} & Valve type & & .04 \\
\hline & Pulmonary homograft conduit & 1.0 & \\
\hline & Aortic homograft conduit & 1.59 & \\
\hline & Porcine valved conduit & 4.08 & \\
\hline & Polystan valved conduit & 5.42 & \\
\hline & "Other" valve types & 0.76 & \\
\hline 3 mo to $<2$ y $(\mathrm{n}=107)$ & Smaller pulmonary valve prosthesis z-score & $0.75 / \mathrm{SD}$ increment & .02 \\
\hline \multirow[t]{11}{*}{$2 \mathrm{y}$ to $<13 \mathrm{y}(\mathrm{n}=456)$} & Male sex & 1.41 & .04 \\
\hline & Smaller pulmonary valve prosthesis z-score & $0.93 / \mathrm{SD}$ increment & .04 \\
\hline & Endovascular stent placement & 2.02 & .02 \\
\hline & Valve type & & .008 \\
\hline & Pulmonary homograft & 1.00 & \\
\hline & Porcine valved implant & 1.12 & \\
\hline & Aortic homograft conduit & 1.87 & \\
\hline & Polystan valved conduit & 3.50 & \\
\hline & Homograft valve implant & 1.97 & \\
\hline & Pericardial valve implant & 1.70 & \\
\hline & Porcine valved conduit & 2.00 & \\
\hline \multirow[t]{6}{*}{$13 \mathrm{y}$ to $65 \mathrm{y}(\mathrm{n}=260)$} & Procedure number: & & .001 \\
\hline & First pulmonary valve & 1.00 & \\
\hline & Second pulmonary valve & 0.55 & \\
\hline & Third pulmonary valve & 8.76 & \\
\hline & Smaller pulmonary valve prosthesis z-score & $0.83 / \mathrm{SD}$ increment & .01 \\
\hline & Endovascular stent placement & 31.0 & .001 \\
\hline
\end{tabular}

$S D$, Standard deviation.

a multivariable analysis of the entire cohort examining the associations between explanatory variables predictive of valve failure was possible. Age, diagnosis, type of valve prosthesis, and endovascular stent placement are associated with prosthesis longevity.

The information regarding risk factors, however, is of limited value to the surgeon faced with the dilemma of choosing the optimum valve prosthesis for an individual patient. Of the important variables identified, age and diagnosis cannot be changed. The choice of prosthesis, however, can be modified, and the data derived from analyzing the entire cohort suggest that pulmonary homograft conduits and possibly porcine valved implants are associated with the longest times to valve or valved conduit replacement. The hazard ratios for other valve prostheses in this population were greater than 1.5 when compared with pulmonary homograft conduits.

We are reluctant, however, to accept this interpretation at face value due to the important influence of age on freedom from valve replacement. As noted in Fig 4, the addition of other variables to the analysis had a very small effect on freedom from valve replacement when compared with age alone. Precisely because the age range is so broad in this cohort and because the influence of age varies so dra- matically across the age spectrum, the concern that the influence of other variables may be important in smaller age subsets is raised. Also, the distribution of the other variables was not homogeneous throughout the age range (eg, porcine valve use was skewed to older age groups as illustrated in Fig 1, A). A complete description of the interaction between age and these other inhomogeneously distributed variables is extremely complex. We chose, instead, to stratify the cohort in a compromise for clarity, albeit with reduced statistical power within each age stratum.

In the clinical arena, an infant may be expected to have different mechanisms of valve failure from those of an adult. Indeed, previous studies have noted that homograft degeneration is accelerated in younger patients, possibly due to age-related immune mechanisms. ${ }^{9,10}$ Others have noted age-related histologic patterns in failed homografts. ${ }^{11}$ It is not surprising, therefore, that different predictors of valve survival may be operative to a greater or lesser degree in different age strata. In the present study, univariable analysis of variables associated with time to valve failure derived different results among the age strata. If an independent investigation was conducted within each age group, different conclusions could be raised. This finding supports the notion that comparison of studies with differ- 
ent age ranges may be problematic when defining variables predictive of valve failure.

In the present study, the use of valve replacement as an indicator of valve failure may be imprecise. A valve prosthesis may become stenotic or insufficient without requiring replacement, thereby representing an echocardiographic failure for a period of time before replacement. ${ }^{10}$ Valve insufficiency or stenosis may be poorly tolerated in a neonate with pulmonary hypertension, mandating early intervention, but relatively well tolerated in older patients and not necessitating intervention. Consequently, use of reoperation as the sole end point for valve failure may fail to detect important valve dysfunction in older patients. Echocardiographic detection of valve dysfunction may be a more sensitive end point when attempting to discriminate between the "life span" of valve prostheses in older age groups.

In the present study, the placement of an endovascular stent was used as an explanatory variable rather than an end point for prosthesis failure. This decision was based on data from this institution suggesting that approximately $50 \%$ of patients undergoing stent placement were free of surgical reintervention at 4 years. ${ }^{12}$ Consequently, the threshold for intervention for stent placement was believed to be somewhat different from the threshold for surgical intervention; therefore, the variables predictive of prosthesis replacement are likely to differ from variables predictive of stent placement.

Death is used as an end point in some studies evaluating valve prostheses. ${ }^{13}$ In the present study, we censored deaths for the following reasons. First, early deaths (eg, <30 days) are unlikely to be caused by degeneration of valve prosthesis function, the end point most commensurate with the objectives of this study. Consequently, the number of deaths due to other causes can be expected to be far greater than the number of deaths due to prosthesis failure in the early postoperative period; therefore, the predictors of early death are likely to be different from predictors of valve prosthesis failure. Late deaths are relatively uncommon events in this study and are commonly due to causes other than valve prosthesis failure. ${ }^{2,4}$

In conclusion, there is a strong relationship between age and failure of pulmonary valve prostheses. Agestratified analysis shows that significant predictors of valve survival vary among clinically relevant age groups. Although analysis of the database subsets results in loss of statistical power, the method allows identification of changing patterns of predictive variables across the age spectrum. Consequently, comparison between studies of valve survival in the literature are problematic if even small differences are present in

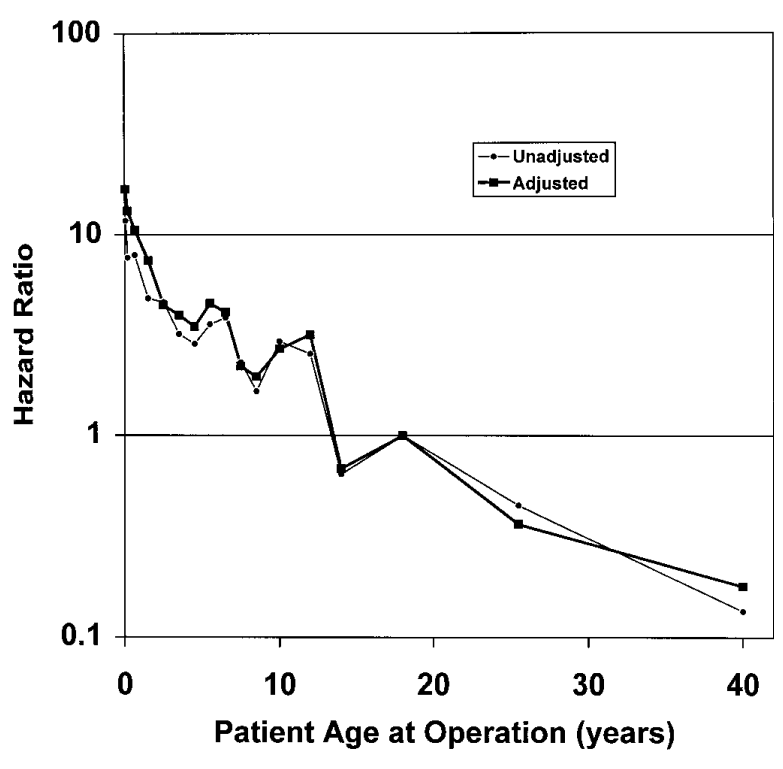

Fig 4. Adjusted and unadjusted hazard ratios for time to valve replacement based on age at surgery (from multivariable Cox proportionate hazard modeling; variables adjusted for in the model include sex, cardiac diagnosis, valve type, pulmonary valve prosthesis z-score, and valve type). The vertical axis represents the hazard ratio for risk of valve failure with a reference category of 15 to 18 years of age.

the age of the populations studied. More precise identification of the important variables predictive of valve survival within different age strata will shed light on the mechanisms operating within the age strata and ultimately will improve the surgeon's ability to decide which size and type of valve or valved conduit to use in individual patients.

We thank Derek Stephens, MSc, for his assistance with this investigation.

\section{REFERENCES}

1. Danielson GK, Anderson BJ, Schlek CD, Ilstrup DM. Late results of pulmonary ventricle to pulmonary artery conduits. Sem Cardiovasc Surg 1995;7:162-7.

2. Cleveland DC, Williams WG, Razzouk AJ, Trusler GA, Rebeyka IM, Duffy L, et al. Failure of cryopreserved allograft valved conduits in the pulmonary circulation. Circulation 1992;86 (Suppl):II-150-3.

3. Razzouk AJ, Williams WG, Cleveland DC, Coles JG, Rebeyka IM, Trusler GA, et al. Surgical connections from ventricle to pulmonary artery: comparison of four types of implants. Circulation 1992;86(Suppl):II-154-8.

4. Sano D, Kark TR, Mee RB. Extracardiac valved conduits in the pulmonary circuit. Ann Thorac Surg 1991;52:285-90.

5. Leblanc JG, Russell JL, Sett SS, Potts JE. Intermediate follow-up 
of right ventricular outflow tract reconstruction with allograft conduits. Ann Thorac Surg 1998;66:S174-8.

6. Niwaya K, Knott-Craig CJ, Lane MM, Chandrasekaren K, Overholt ED, Elkins RC. Cryopreserved homograft valves in the pulmonary position: risk analysis for intermediate-term failure. $\mathrm{J}$ Thorac Cardiovasc Surg 1999;117:141-7.

7. Weipert J, Meisner H, Mendler N, Haehnel JC, Homann M, Paek $\mathrm{S}$, et al. Allograft implantation in pediatric cardiac surgery: surgical experience from 1982-1994. Ann Thorac Surg 1995;60:S1014

8. Rowlatt JF, Rimoldi JHA, Lev M. The quantitative anatomy of the normal child's heart. Pediatr Clin North Am 1963;10:499504.

9. Albert JD, Bishop DA, Fullerton DA, Campbell DN, Clarke DR Conduit reconstruction of the right ventricular outflow tract: lessons learned in a twelve-year experience. J Thorac Cardiovasc Surg 1993;106:228-36.

10. Baskett RJ, Ross DB, Nanton MA, Murphy DA. Factors in the early failure of cryopreserved homograft pulmonary valves in children: preserved immunogenicity. J Thorac Cardiovasc Surg 1996;112:1170-9.

11. Rajani B, Mee RB, Ratliff NB. Evidence for rejection of homograft cardiac valves in infants. J Thorac Cardiovasc Surg 1998;115:111-7.

12. Ovaert C, Caldarone CA, McCrindle BW, Nykanen D, Freedom RM, Coles JG, et al. Endovascular stent implantation for the management of postoperative right ventricular outflow tract obstruction: clinical efficacy. J Thorac Cardiovasc Surg 1999;118:88693.

13. Stark J, Bull C, Stajevic M, Jothi M, Elliot M, de Leval M. Fate of subpulmonary homograft conduits: determinants of late homograft failure. J Thorac Cardiovasc Surg 1998;115:506-16.

\section{Discussion}

Dr Richard A. Jonas (Boston, Mass). This report must be one of the largest series ever, encompassing 945 operations in 726 patients over a 30-year time frame. Other outstanding characteristics include the wide range of patient ages at surgery and the use of several different types of conduits. A report of this degree of complexity requires highly sophisticated statistical analysis, which Dr McCrindle, a pediatric cardiologist and statistician with great expertise in this area, has indeed brought to bear on the problem.

The most obvious but perhaps also the most predictable finding of your study is that young age at the time of conduit implantation is overwhelmingly the most important predictor of conduit durability. Also not surprising is the finding that a smaller normalized conduit size is associated with need for earlier replacement. In children under 13 years of age, pulmonary homografts tended to be the best choice of conduit, whereas in older children the type of conduit did not affect conduit durability. The results of the study do not challenge currently held beliefs, but rather support them.

Overall, however, the performance of conduits remains suboptimal, and it is important to continue to explore methods for avoiding conduits in young children, or at least methods for incorporating growth potential in the conduits. I am hoping that your analysis of this extensive series may have provided you with insights into some continuing questions regarding conduits that you have briefly mentioned.

Some of these questions are as follows: What should be the indication for conduit replacement? We are all aware that right ventricular outflow obstruction is remarkably well tolerated for many years. After all, the atrial switch experience with transposition has demonstrated that the right ventricle can work at systemic pressure in the majority of patients for decades. What were the usual indications in this series for conduit replacement? Was it $75 \%$ systemic pressure, $90 \%$, or $100 \%$ systemic pressure? How did the coexistence of pulmonary regurgitation influence the decision to replace the conduit? How important is an assessment of right ventricular volume in making this decision, and how do you presently assess right ventricular volume in your patients with conduits to help you with this decision?

Many of your patients had orthotopic pulmonary valve replacements after tetralogy repair. If a patient has had a transannular patch repair of tetralogy, placement of a valve in the right ventricular outflow tract, on the basis of your data, will necessitate future reoperations. What should be the criteria for placement of an orthotopic pulmonary valve? Should they differ from the indications for conduit replacement in a patient in whom some form of conduit connection from the right ventricle to the pulmonary artery is unavoidable?

Finally, stent placement within conduits has generated much enthusiasm over the past 3 or 4 years. Having removed many very heavily calcified conduits and rigid porcine valves containing Dacron conduits, I find it difficult to imagine that stents can have much of an impact on such conduits. How effective do you think stents are in prolonging the life of a conduit? If you do perceive a benefit, can you estimate how great that benefit might be?

Dr Caldarone. Thank you, Dr Jonas. Without question, the indications for a pulmonary valve replacement varied across the time spectrum of the study; over 30 years, the diagnostic modalities certainly would have changed considerably. It would be difficult for me to put a number on the percentage of systemic blood pressure found in the right ventricle that would trigger a valve replacement. I am sure that varied among surgeons and over time.

One of the problems with such a large database is that fine detail and the smaller decision-making with individual subsets are lost. Therefore, I cannot give you a direct answer regarding right ventricular pressure. In general, I would say right ventricular pressures two-thirds to three-quarters systemic was generally used as a trigger for some sort of intervention. How closely that was adhered to, though, would require angiographic data on essentially all of the patients, and we do not have that information in this study.

Indications for valve placement for pulmonary insufficiency in patients with tetralogy of Fallot who have had a transannular patch are also evolving. At present, exercise capacity appears to be a reasonable marker for timing valve placement, but I am sure this indication also has evolved over the past 30 years.

Stent placement for pulmonary valve or conduit stenosis is 
an interesting idea. We recently published a series in which stents were used [Ovaert C, Caldarone CA, McCrindle BW. Endovascular stent implantation for the management of postoperative right ventricular outflow tract obstruction. J Thorac Cardiovasc Surg 1999;118:886-93], and the conclusions of that study were that stents could delay the ultimate valve or conduit replacement for a short time, perhaps $50 \%$ for 4 years. If indeed our age relationship was true, then that would suggest that any palliative procedure that could allow the patient to get older would decrease the risk of failure of the subsequent prosthetic valve replacement. The only way to test that hypothesis would be to actually randomize patients prospectively, and my inclination is that the theory probably would not be validated. I do not think we would actually alter the natural history of this imposed disease by delaying valve replacement with stents.

Sir Magdi Yacoub (London, England). I have a small comment: the patients who died were censored. How many of these patients had an autopsy, and what would the effect on the statistics have been had you considered those patients as valve failures as well?

Dr Caldarone. In designing the study, we spent quite a bit of time discussing whether to include late death as an end point. Our sense was that the variables predictive of a late death were liable to be somewhat different from the variables predicting pulmonary valve deterioration, which was the end point we wanted to evaluate. We believed even more strongly that the variables predictive of an early death after a pulmonary valve replacement in, for instance, a neonate were likely to be very different from factors that would determine long-term pulmonary valve deterioration. For these reasons, we did not use death as an end point.

In the univariable analyses in each age subset, if we included late death as an end point, there was no difference in the results. If we included all deaths, a substantial number of which were early deaths, the only effect was a clouding of the database, which caused us to lose statistical significance in individual age groups. We feel fairly confident that exclusion of death as an end point was reasonable.

Dr Ludwig K. von Segesser (Lausanne, Switzerland). You have clearly shown that repeated reoperations are an increased risk for again having to replace the valves. What is the place for a mechanical valve in an adult who has been operated on, say, 5 times before?

Dr Caldarone. In our series very few mechanical valves had been inserted in the pulmonary circulation, and no device had been implanted in more than 4 patients. Thus, we were not able to analyze the survival of mechanical valve prostheses. In general, our experience with mechanical prostheses in the pulmonary position has been poor.

\section{Authoritative}

The Journal of Thoracic and Cardiovascular Surgery is the most frequently cited thoracic/cardiovascular surgery journal in the Science Citation Index. An article in JTCVS is sited on average almost twice as often as those in the closest cardiothoracic journal. 